\title{
Activation of Protease-Activated Receptor-1 Triggers Astrogliosis after Brain Injury
}

\author{
Olivier Nicole, ${ }^{1,3}$ Anna Goldshmidt, ${ }^{1}$ Cecily E. Hamill, ${ }^{1}$ Scott D. Sorensen, ${ }^{1}$ Aristide Sastre,${ }^{1}$ Polina Lyuboslavsky, ${ }^{1}$ \\ John R. Hepler, ${ }^{1}$ Robert J. McKeon, ${ }^{2}$ and Stephen F. Traynelis ${ }^{1}$ \\ Departments of ${ }^{1}$ Pharmacology and ${ }^{2}$ Cell Biology, Emory University School of Medicine, Atlanta, Georgia 30322, and ${ }^{3}$ Université de Caen, Unité Mixte de \\ Recherche-Centre National de la Recherche Scientifique 6185, 14074 Caen Cedex, France
}

\begin{abstract}
We have studied the involvement of the thrombin receptor [protease-activated receptor-1 (PAR-1)] in astrogliosis, because extravasation of PAR-1 activators, such as thrombin, into brain parenchyma can occur after blood-brain barrier breakdown in a number of CNS disorders. $P A R 1^{-/-}$animals show a reduced astrocytic response to cortical stab wound, suggesting that PAR-1 activation plays a key role in astrogliosis associated with glial scar formation after brain injury. This interpretation is supported by the finding that the selective activation of PAR-1 in vivo induces astrogliosis. The mechanisms by which PAR-1 stimulates glial proliferation appear to be related to the ability of PAR-1 receptor signaling to induce sustained extracellular receptor kinase (ERK) activation. In contrast to the transient activation of ERK by cytokines and growth factors, PAR-1 stimulation induces a sustained ERK activation through its coupling to multiple G-protein-linked signaling pathways, including Rho kinase. This sustained ERK activation appears to regulate astrocytic cyclin D1 levels and astrocyte proliferation in vitro and in vivo. We propose that this PAR-1-mediated mechanism underlying astrocyte proliferation will operate whenever there is sufficient injury-induced blood-brain barrier breakdown to allow extravasation of PAR-1 activators.
\end{abstract}

Key words: protease receptor; thrombin; astrogliosis; trauma; MAP kinase; G-protein

\section{Introduction}

Glial cells participate in several important CNS processes, including ion homeostasis, neurotransmitter uptake, neuromodulation, and neuroinflammation. After traumatic or ischemic brain insults, astrocytes undergo proliferation (Liu et al., 2000), phenotypic changes (Ridet et al., 1997), and cellular hypertrophy. The latter is characterized by increased expression of the astrocyte-specific glial fibrillary acidic protein (GFAP) and emission of GFAP-positive processes. This astrogliosis is a shared feature of acute and chronic neurodegenerative diseases that are characterized by an inflammatory component. Although astrogliosis is typically considered a barrier to repair (Menet et al., 2003; Silver and Miller, 2004), reactive astrocytes also have some regenerative effects (Hatten et al., 1991; Ridet et al., 1997; Fawcett and Asher, 1999; Liberto et al., 2004; Hamill et al., 2005).

The molecular trigger for astrogliosis in vivo remains unknown. In addition to cytokines and growth factors implicated in glial reaction to injury, serine proteases such as thrombin also control astrocyte function (Rogove et al., 1999; Gingrich and Traynelis, 2000; Vivien and Buisson, 2000; Wang et al., 2002a,b; Sorensen et al., 2003; Xi et al., 2003). Thrombin is a serine pro-

Received July 30, 2004; revised March 18, 2005; accepted March 18, 2005.

This work was supported by the National Institutes of Health (C.E.H., J.R.H., R.J.M., and S.F.T.) and the National Alliance for Research on Schizophrenia and Depression (S.F.T.). We thank Dan Brat for critical comments on this manuscript.

Correspondence should be addressed to Dr. Olivier Nicole, Université de Caen, Unité Mixte de Recherche-Centre National de la Recherche Scientifique 6185, Institut Fédératif de Recherche 47, Boulevard H. Becquerel, BP 5229, 14074 Caen Cedex, France. E-mail: onicole@neuro.unicaen.fr.

D0I:10.1523/JNEUROSCI.5200-04.2005

Copyright $\odot 2005$ Society for Neuroscience $\quad$ 0270-6474/05/254319-11\$15.00/0 tease generated by proteolysis of its precursor prothrombin, which is endogenously expressed in the brain (Dihanich et al., 1991; Soifer et al., 1994; Weinstein et al., 1995) and present in blood at micromolar levels (Fenton and Bing, 1986). Extravasation of blood-derived thrombin into CNS parenchyma can influence neuronal survival in brain injury models (Akiyama et al., 1992; Festoff et al., 1992; Cunningham et al., 1993; Nishino et al., 1993; Gingrich and Traynelis, 2000). Although some effects of the thrombin receptor [protease-activated receptor-1(PAR-1)] appear harmful in vivo (Gingrich et al., 2000; Vivien and Buisson, 2000; Junge et al., 2003; Olson et al., 2004), there are instances in which PAR-1 activators appear to serve neuroprotective roles (Shibata et al., 2001; Cheng et al., 2003; Mosnier and Griffin, 2003; Ruf, 2003; Guo et al., 2004), particularly at low concentrations (Donovan and Cunningham, 1998; Striggow et al., 2000). Interestingly, infusion of thrombin into the rat caudate nucleus causes gliosis, infiltration of inflammatory cells, mesenchymal cell proliferation, and angiogenesis (Nishino et al., 1993). These data suggest that thrombin may be a candidate trigger or regulator of gliosis in humans, in which PAR-1 is strongly expressed in resting (Junge et al., 2004) as well as reactive (Hamill et al., 2005) astrocytes. Although the cellular actions induced by thrombin are often linked to activation of PAR-1 signaling through the G-protein subunits $\mathrm{G}_{\beta} \gamma, \mathrm{G} \alpha_{\mathrm{q} /} \mathrm{G} \alpha_{11}, \mathrm{G} \alpha_{\mathrm{i}} / \mathrm{G} \alpha_{\mathrm{o}}$, and $\mathrm{G} \alpha_{12} / \mathrm{G} \alpha_{13}$ (Rasmussen et al., 1991; Wu et al., 1991; Grand et al., 1996; Macfarlane et al., 2001; Mackie et al., 2002), other members of the PAR family may similarly control astrocytic function (Wang et al., 2002a; Sorensen et al., 2003). Moreover, signaling through PAR-1 may vary with the protease activator. We have circumvented the confounds of multiple PARs and protease-specific 
effects by using a genetically altered mouse lacking PAR-1 and a small peptide-selective PAR-1 activator with the amino acid sequence TFLLR-NH $\mathrm{N}_{2}$ (TFLLR) to test specifically whether thrombin extravasation can trigger astrogliosis through PAR-1 activation.

\section{Materials and Methods}

Animals. PAR $1^{-1-}$ and wild-type controls were generated by breeding male PAR1 ${ }^{+/-}$mice, a gift from Dr. Shaun Coughlin (University of California, San Francisco, CA) (Connolly et al., 1996), with female C57BL/6 wild-type mice from The Jackson Laboratory (Bar Harbor, $\mathrm{ME})$. Breeding heterozygous littermates generated homozygous null mutants and genetically matched wild-type controls that were $\geq 99 \%$ C57BL/6. Animals used for these studies were within five generations of the initial homozygous null mutant or wild-type breeding pairs.

Cortical stab wound. All procedures involving the use of animals were approved by the Institutional Animal Care and Use Committee at Emory University. PAR $-1^{-1-}$ or littermate controls were anesthetized with a $1: 1$ mixture of rompun and ketamine $(0.12 \mathrm{ml} / 100 \mathrm{mg})$, a midline incision was made through the scalp, and the skin was retracted laterally. The periosteum was cleaned from the skull, and a rectangular window was drilled over the left cerebral hemisphere, exposing the dura. The implant to be inserted was a specially shaped nitrocellulose filter $(3 \times 3 \mathrm{~mm}$; Millipore, Bedford, MA), which was boiled in several changes of distilled water to remove residual surfactants, dried, and stored at $-20^{\circ} \mathrm{C}$. A number 11 scalpel blade was inserted horizontally into the cortex. The filter implant was then inserted $2-5 \mathrm{~mm}$ into the stab wound with a pair of self-closing forceps. The skin was sutured closed, and, $7 \mathrm{~d}$ after injury, animals were killed and transcardially perfused with $4 \%$ paraformaldehyde (PFA). Each brain was removed and cryoprotected in $20 \%$ sucrose before sectioning at $30 \mu \mathrm{m}$. Brains with malpositioned filters, such as those that came to rest in the meninges or the corpus callosum or those that penetrated the ventricle, were discarded. Some mice received an intrajugular injection of $100 \mu \mathrm{l}$ of $2 \%$ Evan's Blue before cortical stab wound. These mice were killed $2 \mathrm{~h}$ after lesion and perfused with cold PBS and subsequently with 4\% PFA. Brains were sectioned at $350 \mu \mathrm{m}$ on a vibratome and evaluated for Evan's Blue extravasation.

Agonist injection. Mice were initially anesthetized with 5\% isoflurane and maintained with $2 \%$ isoflurane during surgery. Body temperature was held at $37^{\circ} \mathrm{C}$ with a thermostatic heating pad. The head was fixed to a mouse stereotaxic frame, a burr hole was drilled, and a 33 gauge injection needle was lowered into the right cortex (anterior, $0.0 \mathrm{~mm}$; lateral, $2.0 \mathrm{~mm}$; and ventral, $1.0 \mathrm{~mm}$ from bregma) (Ayata et al., 1997). Drug or PBS plus $0.1 \%$ lipid-free bovine serum albumin (BSA) was injected in a volume of $0.5 \mu$ l over 5 min using a Hamilton syringe, and the needle was left in place for an additional $5 \mathrm{~min}$. Animals were killed $5 \mathrm{~d}$ after injection and perfused, and brains were sectioned at $20 \mu \mathrm{m}$.

A separate set of mice received intrastriatal TFLLR injections, followed by intraperitoneal administration of 5-bromo-2'-deoxyuridine (BrdU) (Sigma, St. Louis, MO), which was dissolved in water at a concentration of $10 \mathrm{mg} / \mathrm{ml}$. Each animal received one BrdU injection of $50 \mu \mathrm{g} / \mathrm{g}$ body weight immediately after surgery and then once every $12 \mathrm{~h}$ for $5 \mathrm{~d}$, for a total of 11 injections. This deeper brain region was analyzed for astrocytic BrdU incorporation to minimize any potential effects from the surgery at the dura on gliosis and cell division. To obtain representative results, all striatal sections separated by a distance of $100 \mu \mathrm{m}$ were analyzed, and only astrocytic profiles with a clearly visible nucleus were counted.

Immunostaining. For BrdU staining, mouse brain sections and cell cultures fixed in $4 \%$ PFA were washed with PBS, incubated in $1 \mathrm{~N} \mathrm{HCl}$ solution for $1 \mathrm{~h}$ at $42^{\circ} \mathrm{C}$, neutralized with $0.1 \mathrm{~N}$ borate buffer for $15 \mathrm{~min}$, washed three times with PBS, and incubated for $30 \mathrm{~min}$ in 1:100 antiBrdU antibody (unlabeled or conjugated to Alexa Fluor 488; Molecular Probes, Eugene, OR) diluted in 0.5\% BSA and 0.5\% Tween 20. For GFAP staining, mouse brain sections and cell cultures were incubated in blocking solution containing 5\% normal goat serum (Jackson ImmunoResearch, West Grove, PA), $0.5 \%$ BSA, and $0.25 \%$ Triton X-100 for $1 \mathrm{~h}$ at room temperature. Brain sections were subsequently incubated in rabbit anti-GFAP (1:500; Sigma) in the blocking solution overnight at $4^{\circ} \mathrm{C}$, whereas cell cultures were incubated with the same antibody for $1 \mathrm{~h}$ at room temperature. Brain sections and cell cultures were then washed three times in PBS and incubated in a Marina Blue- (Molecular Probes), Texas Red-, or FITC- (Jackson ImmunoResearch) conjugated secondary antibody in blocking solution for $1 \mathrm{~h}$ at room temperature.

Astrocyte and microglia cultures. Astrocyte cultures were prepared from postnatal day 1 (P1)-P3 mice, as described previously (Rose et al., 1993). The cerebral cortices of newborn mice were isolated from adherent meninges, and the tissue was minced and dissociated into a single-cell suspension by trituration through a Pasteur pipette. Dissociated cortical cells were grown in multiwell plates coated with $100 \mu \mathrm{g} / \mathrm{ml}$ poly-D-lysine using DMEM (25 mM glucose) supplemented with 10\% horse serum, $10 \%$ fetal bovine serum, $2 \mathrm{~mm}$ glutamine, and $10 \mathrm{U} / \mathrm{ml}$ penicillin with 10 $\mu \mathrm{g} / \mathrm{ml}$ streptomycin. After $2 \mathrm{~d}$, cultures were vigorously shaken to remove all loosely adherent cells. Cultures were maintained at $37^{\circ} \mathrm{C}$ in a humidified 5\% $\mathrm{CO}_{2}$-containing atmosphere until they reached $50 \%$ confluency ( $7 \mathrm{~d}$ in vitro). Astrocyte cultures were $>95 \%$ pure based on analysis of GFAP staining.

For microglia-astrocyte cocultures, astrocyte cultures were prepared as detailed above, omitting the shaking, and, after 2 weeks, floating microglia were harvested and applied onto 5- to 7-d-old 50\% confluent astrocytes. Microglia were allowed to adhere for $24 \mathrm{~h}$ before use. Purity of harvested microglia was $>95 \%$ as determined by plating a portion of microglia onto clean coverslips and staining with isolectin GS-IB4 from Griffonia simplicifolia conjugated to Alexa Fluor 594 (Molecular Probes).

Migration assay. A monolayer of astrocytes was grown and wounded by scratching. The cultures were treated with serum, TFLLR $(30 \mu \mathrm{M})$, or buffer. To prevent proliferation, cells were treated during the experiment with cytosine $\beta$-D-arabinofuranoside (AraC; $10 \mu \mathrm{m}$; Sigma), which inhibits DNA synthesis.

Proliferation assay by BrdU incorporation. Astrocytes or astrocyte-microglia cocultures were deprived of serum for $24 \mathrm{~h}$ before treatment. $\operatorname{BrdU}(30 \mu \mathrm{M})$ was included for the last $2 \mathrm{~h}$ of agonist application before fixation with cold 4\% PFA. Cells incorporating BrdU were identified using anti-BrdU staining, as detailed above, and counted at $10 \times$ magnification. Experiments were performed in triplicate from at least two independent dissections, and counts from two or more fields per well were averaged and reported as percentage change from control.

SDS-PAGE and Western blot. After stimulation, the cultured murine cortical astrocytes were lysed in a radioimmunoprecipitation assay buffer (PBS, 1\% Igepal-CA630, 0.5\% sodium deoxycholate, and 0.1\% SDS) freshly supplemented with $1 \mathrm{~mm}$ sodium orthovanadate, $0.1 \mathrm{~g} / \mathrm{ml}$ PMSF, and aprotinin. The cell lysate was gently shaken on a rocker for $15 \mathrm{~min}$ at $4^{\circ} \mathrm{C}$ and centrifuged at $10,000 \mathrm{rpm}$ for $15 \mathrm{~min}$. The supernatant was immediately transferred to a fresh tube, and the pellet was discarded. The protein concentration was measured by Bradford's method using BSA as the standard. An equivalent amount of protein from each sample was resolved using PAGE (15\%) and subsequently transferred to polyvinylidene difluoride (PVDF) membranes. After blocking of nonspecific protein binding with $5 \%$ nonfat dry milk, blots were incubated with a primary antibody against phosphorylated extracellular-signal-regulated kinase (p-ERK) (1:200; Santa Cruz Biotechnology, Santa Cruz, CA), GFAP (1:10,000; Sigma), or cyclin D1 (1:2000; Cell Signaling Technology, Beverly, MA), followed by incubation with the appropriate secondary peroxidase-conjugated antibody and detection using a chemiluminescence kit (Amersham Biosciences, Arlington Heights, IL). Film exposure time was limited so that signals remained in the linear response range of the film. Blots were scanned, and intensity of bands was measured using NIH Image software. After detection, the blot was then incubated in stripping buffer ( $62 \mathrm{~mm}$ Tris $\mathrm{HCl}, \mathrm{pH} 6.8,2 \%$ SDS, and 100 mM $\beta$-mercaptoethanol) for $30 \mathrm{~min}$ at $50^{\circ} \mathrm{C}$, followed by incubation with TBS containing $0.1 \%$ Tween 20 and 5\% dry milk. The blot was then incubated with ERK polyclonal antibody (Santa Cruz Biotechnology) that binds to ERK1 and ERK2.

Reverse transcription-PCR. Total RNA was isolated from murine cell cultures through the use of the Trizol kit (Invitrogen, Carlsbad, CA). One microgram of total RNA was reverse transcribed into cDNA using poly(dT) oligonucleotides that allow a specific targeting of poly $\left(\mathrm{A}^{+}\right)$ mRNA. An aliquot of the cDNA library $(1 \mu \mathrm{l})$ was amplified by PCR with 


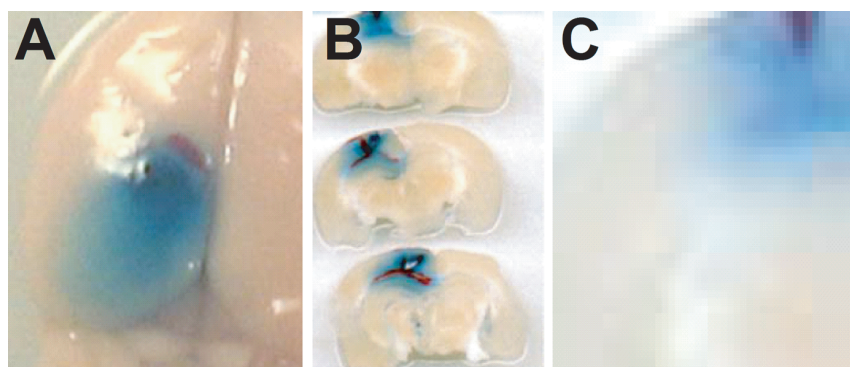

Figure 1. Cortical stab wound involves breakdown of the blood - brain barrier. C57BL/6 mice received an intrajugular injection of $100 \mu$ l of $2 \%$ Evan's Blue 20 min before receiving a cortical stab wound. $\boldsymbol{A}, \boldsymbol{B}$, Two hours later, animals were perfused, and the brain was removed $(\boldsymbol{A})$ and sectioned at $350 \mu \mathrm{m}$ on a vibratome ( $\boldsymbol{B}$ ). $\boldsymbol{C}$, Evan's Blue extravasation was clearly evident in the area surrounding the lesion.

specific sets of oligonucleotides: $\beta$-actin sense, 5'-GTGGGCCGCTCTAGGCACAA-3; $\beta$-actin antisense, 5 '-CTCTTGATGTCACGACGATTTC-3' (Ali et al., 2000); cyclin D1 sense, 5'-ATGGAACACCAGCTCCTG-3'; cyclin D1 antisense, 5'-CCAGACCAGCCTCTTCC-3' (Dyer and Cepko, 2001); PAR-1 sense, 5' -GCCCCGGCGCTTGCTGAT-3'; and PAR-1 antisense, 5'-CACCACGGCCGGCTTCTTGA-3'. Amplification conditions using a Minicycler thermocycler (MJ Research, Watertown, MA) were as follows: $95^{\circ} \mathrm{C}$ for $30 \mathrm{~s}, 55^{\circ} \mathrm{C}$ for $30 \mathrm{~s}$, and $72^{\circ} \mathrm{C}$ for $60 \mathrm{~s}$. Amplified products were separated by agarose gel electrophoresis and visualized by ethidium bromide staining. The levels of cyclin D1 expression have been analyzed, and the procedures have been standardized relative to actin expression levels.

Statistics. Statistical evaluation was performed using Student's $t$ tests or ANOVA with Bonferroni-Dunn's post hoc test, where appropriate; $p<$ 0.05 was considered to be significant. Data are given as mean \pm SEM.

\section{Results}

Role of PAR-1 in astrogliosis

To directly test whether PAR-1 activation contributes to glial scar formation, we evaluated astrogliosis in an

A
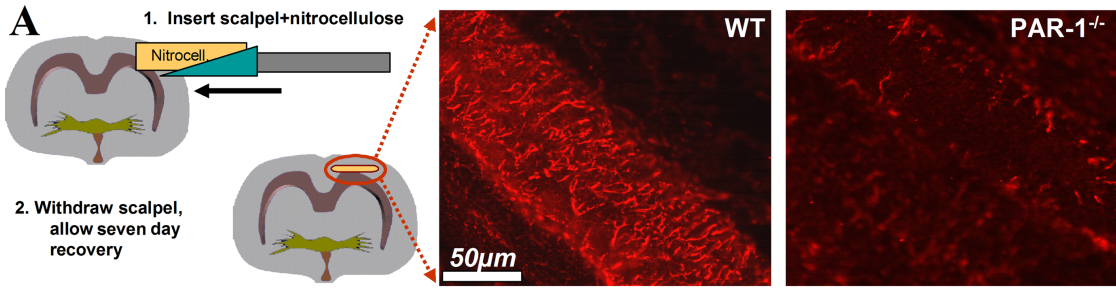

B
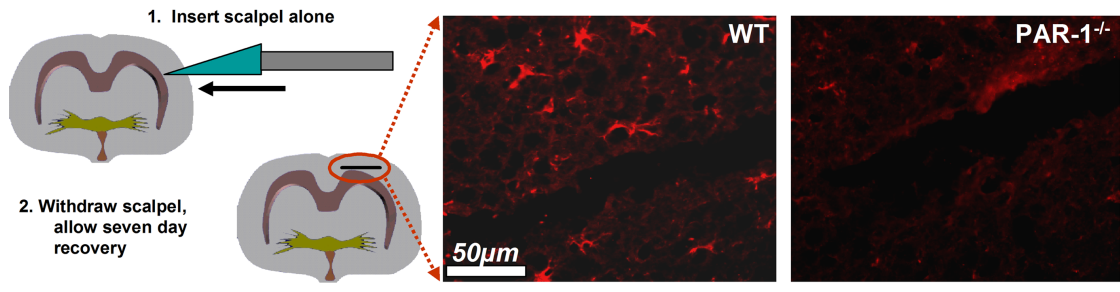

C
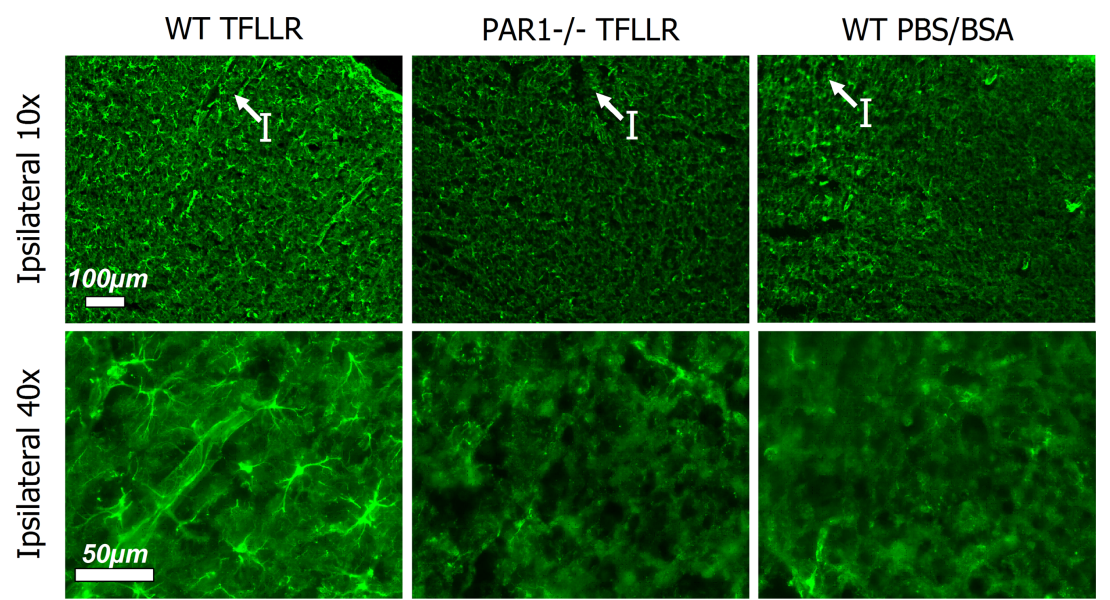

Figure 2. Effect of PAR-1 activation on astrogliosis. A, GFAP immunohistochemistry was performed on brain sections from wild-type and $P A R 1^{-1-}$ mice $7 \mathrm{~d}$ after nitrocellulose filter insertion. High levels of GFAP reactivity can be seen in astrocytes at the surface of the filter only when the implantation of filter was performed in cerebral cortex of wild-type (WT) mice ( $n=6$ mice for each condition). B, GFAP immunohistochemistry was performed on the brain sections from wild-type and PAR1 ${ }^{-1-}$ mice $7 \mathrm{~d}$ after cortical stab wound without nitrocellulose. High levels of GFAP reactivity can be seen in astrocytes extending radially away from the lesion in cerebral cortex of wild-type but not PAR1 ${ }^{-1-}$ mice $\left(n=3 \mathrm{WT} ; n=2 P A R 1^{-/-}\right.$mice). C, GFAP immunohistochemistry was performed on $20 \mu \mathrm{m}$ mouse brain sections $5 \mathrm{~d}$ after an intracortical injection (I) of TFLLR (10 nmol; left and middle panels) or vehicle (PBS- $0.1 \%$ BSA; right panels) in a volume of $0.5 \mu$ l over 5 min using a Hamilton syringe ( $n=2-4$ animals per condition). TFLLR injection caused increased GFAP reactivity in the ipsilateral cortex of wild-type animals compared with the ipsilateral cortex of $P A R 1^{-/}$animals, the contralateral cortex of wild-type animals (data not shown), and vehicle injections. The bottom row shows a representative region at $40 \times$. in vivo model of cortical injury in $P A R 1^{-1-}$ mice and littermate wild-type controls (Connolly et al., 1996). In this model, a cortical stab wound is accompanied by hemorrhage, thrombosis, and extravasation of large-molecular-weight plasma proteins. Figure 1 shows the extensive intraparenchymal penetration of extravasated Evan's Blue-bound albumin $2 \mathrm{~h}$ after injury (representative of six animals); sham-operated animals $(n=3)$ showed little or no cortical extravasation of Evan's Blue-bound albumin.

Because increased GFAP immunoreactivity has been used extensively as a diagnostic feature for CNS reactive gliosis, we used GFAP immunostaining to compare the astrocytic reaction to a cortical stab wound between wild-type and $P A R 1^{-/-}$ mice (Rudge et al., 1989) (Fig. 2A,B) $(n=$ 6 ). A nitrocellulose filter was used to assist in identifying the cortical stab wound during sectioning many days after injury. Seven days after filter insertion in wildtype mice, a high level of GFAP reactivity could be seen in astrocytes at the surface of the filter insert. Strong GFAP immunoreactivity was absent or greatly reduced $7 \mathrm{~d}$ after filter implantation in the cerebral cortex of $P A R 1^{-1-}$ mice (Fig. $2 A$, right) $(n=6)$. To eliminate any potential effects of nitrocellulose, the same stab wound was made in wild-type mice without filter implantation and caused an increase in GFAP-positive astrocytes extending radially away from the lesion (Fig. $2 B)(n=3)$. Evaluation of $P A R 1^{-1-}$ animals showed a dramatic reduction in GFAP immunoreactivity in response to injury (Fig. $2 B$ ) $(n=2)$, indicating that PAR-1 activation may be important for gliosis.

To evaluate the participation of PAR-1 activation in glial scar formation, astrocytic reactions to intracortical injection of 


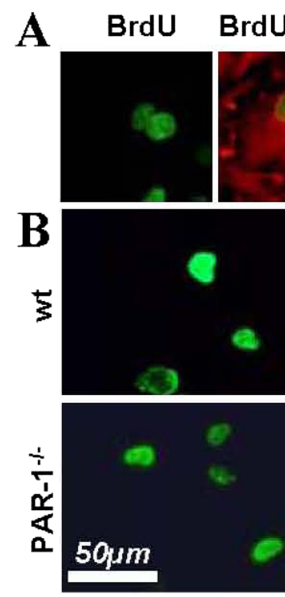

Control
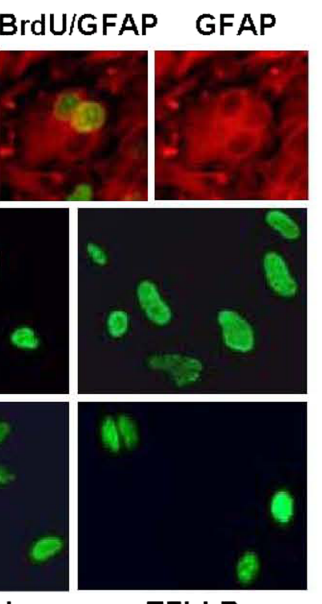

TFLLR

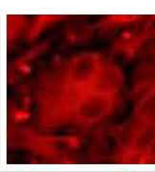

AP

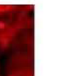

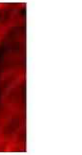

C

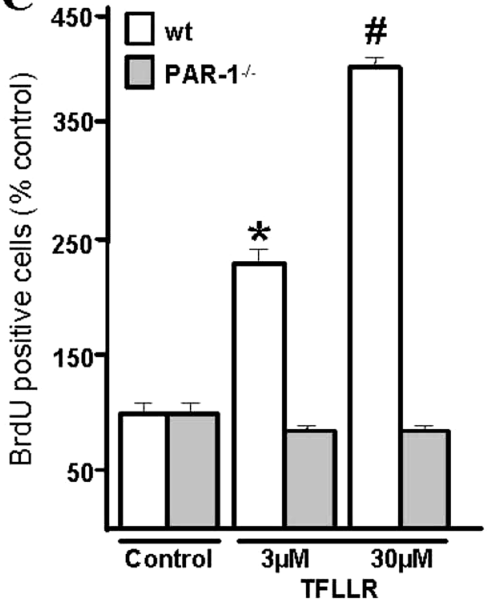

D

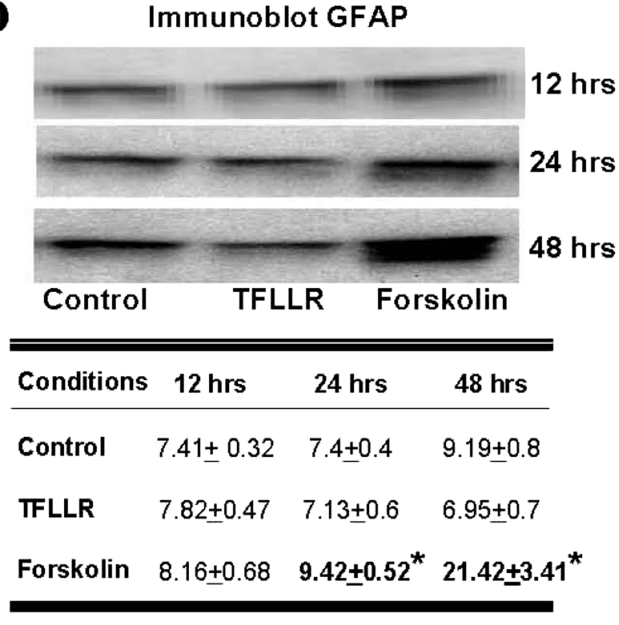

E
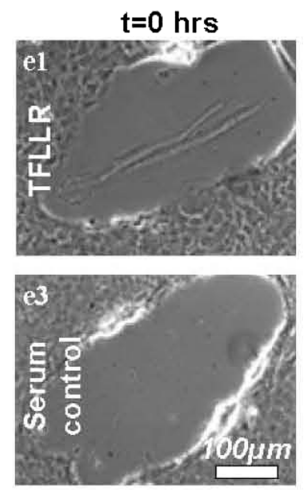

Astrocyte Migration in vitro

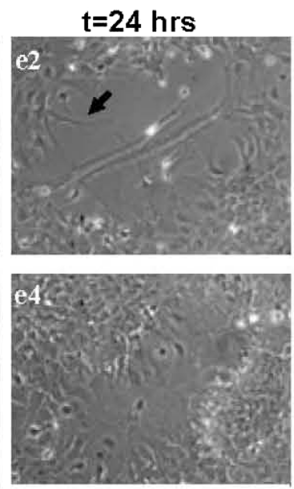

F
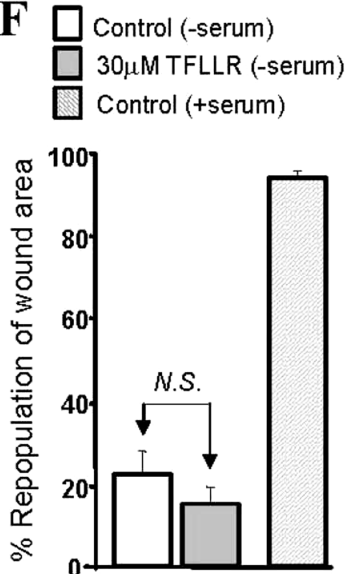
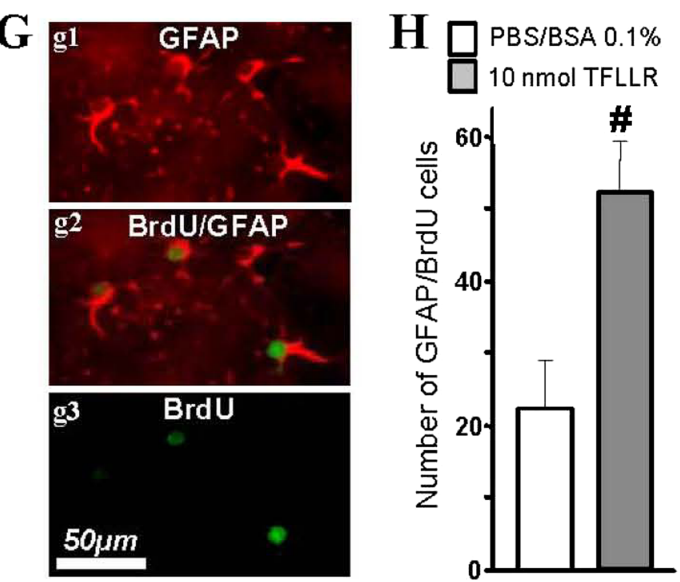

Figure 3. PAR-1 activation induces astrocyte proliferation. $A$, Images of BrdU (FITC) and GFAP (Texas Red) immunofluorescence show that all BrdU-containing cells are immunoreactive for GFAP. $B$, Fluorescent image analysis of cortical astrocytes labeled for BrdU in control condition or after treatment with TFLLR $(30 \mu \mathrm{M})$ suggests that application of TFLLR increases the number of BrdU-positive cells only in wild-type (wt), but not in $P A R 1^{-/-}$, astrocytes. C, Proliferation is shown as the percentage change in the number of BrdU-positive cells compared with control (mean \pm SEM; ${ }^{*} p<0.05 ; " \#<0.01$; unpaired $t$ test; $\left.n=10\right)$. $\boldsymbol{D}$, Cortical astrocytes were treated with TFLLR $(30 \mu \mathrm{M})$ or forskolin $(50 \mu \mathrm{M})$ for 12,24 , or $48 \mathrm{~h}$. Five micrograms of protein were separated by SDS-PAGE, transferred to nitrocellulose filters, and probed with anti-GFAP antibody. The application of TFLLR did not significantly modify the protein level of GFAP ( $n=3$ ). In this experiment, forskolin treatment served as a positive control $\left({ }^{*} p<0.05 ; n=3\right)$. The immunoblot shown is representative of three independent experiments; the results of densitometry are tabulated. $\boldsymbol{E}$, A monolayer of astrocytes was wounded by scratching and treated with serum, TFLLR $(30 \mu \mathrm{M})$, or buffer, all in the presence of AraC (see Materials and Methods). Photomicrographs show the migration of astrocytes to the wound area at $0 \mathrm{~h}(\boldsymbol{e} \mathbf{1}, \mathbf{e} 3)$ and at $24 \mathrm{~h}(\mathbf{e} 2, \boldsymbol{e} 4)$ after $\operatorname{TFLLR}(\boldsymbol{e} \mathbf{1}, \mathbf{e 2})$ or $10 \% \mathrm{FBS}(\boldsymbol{e} \mathbf{3}, \mathbf{e} 4)$. $\boldsymbol{F}$, There was no significant difference $(p>0.05$; unpaired $t$ test) in wound closure (percentage of area recovered after $24 \mathrm{~h}$ of treatment) between vehicle and TFLLR in the absence of serum. Serum treatment served as a positive control and strongly stimulated repopulation of the injured area ( $p<0.001$; unpaired $t$ test). Data shown are percentage of area recovered ( $n=10-12)$. N.S., Not significant. G, TFLLR or vehicle was injected into the right striatum (anterior, $0.9 \mathrm{~mm}$; lateral, $2.0 \mathrm{~mm}$; and ventral, $2.5 \mathrm{~mm}$ from bregma) in a volume of $0.5 \mu$ l over 5 min using a Hamilton syringe (33 gauge needle). The animal received one intraperitoneal injection of $50 \mu \mathrm{g} / \mathrm{g}$ BrdU immediately after surgery and then every $12 \mathrm{~h}$ for $5 \mathrm{~d}$, for a total of 11 injections. Animals were perfusion fixed at $5 \mathrm{~d}$. GFAP and BrdU immunohistochemistry was performed on brain sections ( $20 \mu \mathrm{m}$ ) $5 \mathrm{~d}$ after injection. With this procedure, the cytoplasm of astrocyte cells was stained red $(\boldsymbol{g} \mathbf{1}, \boldsymbol{g} \mathbf{2})$ and the nuclei of proliferating cells were stained green $(\boldsymbol{g} \mathbf{2}, \boldsymbol{g} \mathbf{3})$. $\boldsymbol{H}$, Cell counts were performed in five fields of five independent slices per animal (separated by a distance of $50 \mu \mathrm{m}$ around the injection site). The number sign indicates a significant difference from PBS/BSA injection. All experimentation and analysis were performed blind. A total of three TFLLR-treated mice plus three PBS- $0.1 \%$ BSA-treated control animals were analyzed. Error bars represent SEM.

$10 \mathrm{nmol}$ of the selective PAR-1 agonist TFLLR were studied in $P A R 1^{-/-}$mice as well as wild-type littermate control mice. The selectivity of TFLLR was confirmed by comparison of the calcium response between astrocytes from wild-type and $P A R 1^{-1-}$ mice ( $n=3$; data not shown). Five days after TFLLR injection, a marked increase in GFAP immunoreactivity was evident in the ipsilateral (Fig. $2 C$, left panels) $(n=3)$, but not contralateral $(n=$ 3 ; data not shown), cortex of wild-type mice. However, no enhancement of GFAP immunoreactivity was found in $P A R 1^{-/-}$ mice injected with TFLLR (Fig. $2 C$, middle panels) $(n=3)$ or in wild-type animals injected with buffer (PBS-BSA $0.1 \% ; n=3$ ) (Fig. $2 C$, right panels). Together, these data suggest an important role for PAR-1 activation in reactive gliosis and scar formation.
Cellular mechanism underlying PAR-1-triggered astrogliosis During the early phase of astrogliosis (3-5 d after injury), reactive astrocytes increase expression of the structural protein GFAP and begin to populate the periphery of the damaged region by proliferation and migration from adjacent regions (Ridet et al., 1997; Matyash et al., 2002). We considered three ways by which PAR-1 activation might contribute to astrogliosis: PAR-1 activation could stimulate astrocyte proliferation, GFAP expression, and/or migration. We tested each of these possibilities in primary cultures of murine astrocytes. First, cultured astrocytes were challenged with either 3 or $30 \mu \mathrm{M}$ TFLLR, and proliferation was monitored by the incorporation of BrdU into newly synthesized DNA of dividing cells (Fig. $3 A, B$ ). TFLLR induced a dose-dependent 

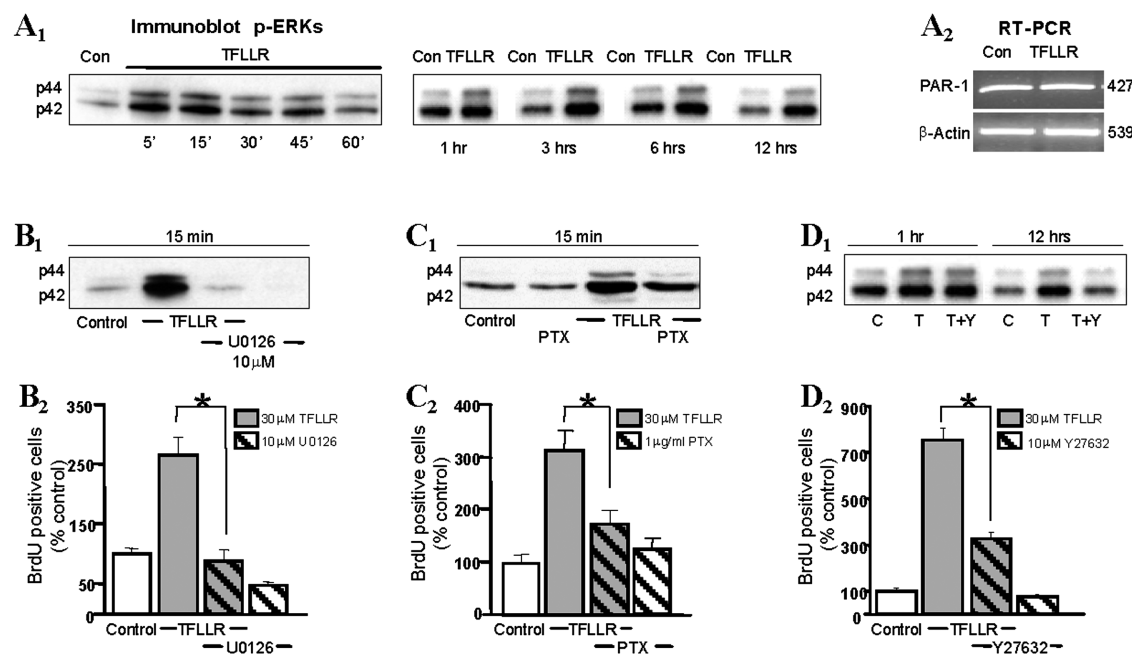

Figure 4. ERK activation is involved in PAR-1-induced astrocyte proliferation. $\boldsymbol{A}_{\boldsymbol{1}}$, Serum-starved primary cortical astrocytes were treated with TFLLR $(30 \mu \mathrm{m})$ for indicated times. Aliquots of whole-cell lysates were separated by SDS-PAGE, transferred to PVDF membranes, and incubated with the anti-p-ERK antibody. The immunoblots are representative of three independent experiments. Con, Control. $\boldsymbol{A}_{2}$, Total RNA was extracted from cultured cortical astrocytes treated with vehicle or TFLLR $(30 \mu \mathrm{M})$ and subjected to RT-PCR for PAR-1 and $\beta$-actin transcripts. This figure is representative of three experiments. $\boldsymbol{B}_{\boldsymbol{1}}$, Primary cortical astrocytes were treated for $15 \mathrm{~min}$ with TFLLR $(30 \mu \mathrm{M})$ in the presence of U0126 (10 $\mu \mathrm{m} ; 30 \mathrm{~min}$ before and during). Aliquots of whole-cell lysates were separated by SDS-PAGE, transferred to membranes, and incubated with the p-ERK. A representative immunoblot is shown demonstrating the specific blockage of ERK phosphorylation by U0126 treatment $(n=3)$. $\boldsymbol{B}_{\mathbf{2}}$, Treatment (30 min before and during $24 \mathrm{~h}$ ) of cortical astrocytes with U0126 (10 $\mu \mathrm{m})$ reduced the TFLLR-induced proliferation, as determined by counting of BrdU-positive cells. The proliferation is given as the percentage change compared with control $\left(n=6 ;{ }^{*} p<0.001\right.$; unpaired $t$ test). $\boldsymbol{C}_{1}$, Primary cortical astrocytes were treated for $15 \mathrm{~min}$ with TFLLR (30 $\left.\mu \mathrm{m}\right)$ in the presence of PTX $(1 \mu \mathrm{g} / \mathrm{ml}$ overnight before). Aliquots of whole-cell lysates were separated by SDS-PAGE, transferred to membranes, and incubated with the p-ERK. A representative immunoblot shows a reduction of ERK phosphorylation by PTX treatment $(n=3)$. $\boldsymbol{C}_{2}$, Pretreatment (24 h) of primary cortical astrocytes with PTX $(1 \mu \mathrm{g} / \mathrm{ml})$ reduced TFLLR-induced proliferation, as determined by counting of BrdUpositive cells $\left(n=10\right.$; ${ }^{*} p<0.05$; unpaired $t$ test). $\boldsymbol{D}_{1}$, Cortical astrocytes were pretreated with vehicle control (C) or Y27632 (Y; $10 \mu \mathrm{m})$ for $12 \mathrm{~h}$ before TFLLR $(\mathrm{T} ; 30 \mu \mathrm{m})$. Aliquots of whole-cell lysates at indicated time of TFLLR incubation were separated by SDS-PAGE, transferred to nitrocellulose membranes, and incubated with the p-ERK. A representative immunoblot is shown demonstrating that pretreatment with Y27632 had no effect on the early phase of TFLLR-induced ERK activation (after $1 \mathrm{~h}$ of treatment), but completely blocks the sustained ERK activation $(12 \mathrm{~h})(n=3) . \boldsymbol{D}_{2}$, The pretreatment $(24 \mathrm{~h})$ of cortical astrocytes with Y27632 $(10 \mu \mathrm{m})$ reduced the TFLLR-induced proliferation, as determined by counting of BrdU-positive cells $\left(n=6\right.$; ${ }^{*} p<$ 0.05 ; unpaired $t$ test). Error bars represent SEM.

increase in BrdU incorporation into cultured astrocytes from wild-type, but not from $P A R 1^{-1-}$ (Fig. $3 C$ ). Second, we determined the effect of TFLLR on GFAP expression in astrocyte cultures using Western immunoblots. Treatment of cells with forskolin $(50 \mu \mathrm{M})$, which is known to increase GFAP levels in astrocytes (Kaneko et al., 1994), increased GFAP immunoreactivity at 24 and $48 \mathrm{~h}(p<0.05$; unpaired $t$ test; $n=3)$ (Fig. $3 D)$, confirming our ability to measure changes in GFAP. However, in side-by-side experiments with forskolin, TFLLR did not significantly alter the level of GFAP immunoreactivity (unpaired $t$ test; $n=3$ at each time point). Third, we examined the effect of TFLLR on astrocyte motility, which could also play an important role in astrocytic response to injury (Matyash et al., 2002). To examine the role of PAR-1 activation on astrocyte migration, we used an in vitro wound-healing model (Hou et al., 1995) in which a cell-free zone was created within a confluent astrocyte monolayer. We subsequently analyzed by time-lapse microscopy the degree to which astrocytes repopulated the cell-free zone at 0 and $24 \mathrm{~h}$ under different experimental conditions. To eliminate the contribution of cell proliferation to wound closure, all experiments were performed in the presence of $10 \mu \mathrm{M}$ AraC. As described previously (Matyash et al., 2002), we observed lamellipodial extension of cells (Fig. 3E, arrowhead) located in the immediate vicinity to the wound margin. As summarized in Figure $3 F$,

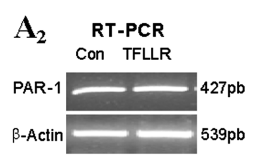

$\sim 22 \%$ of the wound area was repopulated within $24 \mathrm{~h}$ in the absence of serum, and TFLLR $(30 \mu \mathrm{M})$ did not significantly alter the degree of repopulation at $24 \mathrm{~h}$ compared with serum-free control $(n=10-$ 12). Application of serum served as a positive control and stimulated an increase in astrocyte motility that resulted in 95\% wound closure $(p<0.0001$; unpaired $t$ test). Thus, PAR-1 signaling does not appear to alter the migratory processes of astrocytes in vitro.

Together, these results suggest that PAR-1 activation may contribute to glial scar formation through stimulation of astrocyte proliferation rather than through enhanced migration to the injured area or upregulation of GFAP. To test whether PAR-1 can influence proliferation in vivo, animals received one intrastriatal injection of TFLLR $(0.5 \mu \mathrm{l} / 10 \mathrm{nmol} / 5 \mathrm{~min})$ or vehicle $(0.5 \mu \mathrm{l}$ PBS-0.1\% BSA/5 min) and were subsequently pulsed with BrdU to mark newly proliferating cells. To determine whether these newly generated cells within the glial scar had differentiated into astrocytes, double immunostaining for GFAP/BrdU was performed $5 \mathrm{~d}$ after injection (Fig. 3G). Increased numbers of GFAP- and BrdU-positive cells were present around the TFLLR injection site when compared with vehicle injection site. Furthermore, the areas that showed the strongest GFAP immunoreactivity coincided with the highest BrdU staining ( $p<$ 0.01 ; unpaired $t$ test) (Fig. $3 H$ ), confirming in vivo that the activation of thrombin receptor PAR-1 induces the proliferation of astrocytes. Cresyl violet staining in parallel slices was homogenous, suggesting that changes did not result from nonspecific neuronal injury at the site of injection (data not shown).

\section{Biochemical mechanism underlying PAR-1-triggered astrocyte proliferation}

Several studies, mostly in cell lines, suggest that the activation of mitogen-activated protein kinase (MAPK) (also known as ERK) is required for cell proliferation (Roovers and Assoian, 2000). To examine whether stimulation of PAR-1 can elicit ERK phosphorylation and activation in astrocytes, we challenged serum-starved astrocytes with TFLLR $(30 \mu \mathrm{M})$ for varying lengths of time, ranging from $15 \mathrm{~min}$ to $24 \mathrm{~h}$, and quantified by immunoblot the amount of phosphorylated ERK (p42 and p44). As shown in Figure $4 A_{1}$, TFLLR induced a time-dependent increase in ERK phosphorylation in primary cultured astrocytes. TFLLR stimulated a strong early peak of ERK activation, which declined over $1 \mathrm{~h}(n=3)$. Because recent studies have demonstrated that the duration of ERK activation seems to control cell proliferation (Weber et al., 1997; Bottazzi et al., 1999; Roovers et al., 1999), we determined the time course of PAR-1 agonist-induced ERK phosphorylation over $12 \mathrm{~h}$. After the initial response, we found a second phase of persistent ERK activation above basal at $12 \mathrm{~h}$ (Fig. $\left.4 A_{1}\right)(n=3)$. 

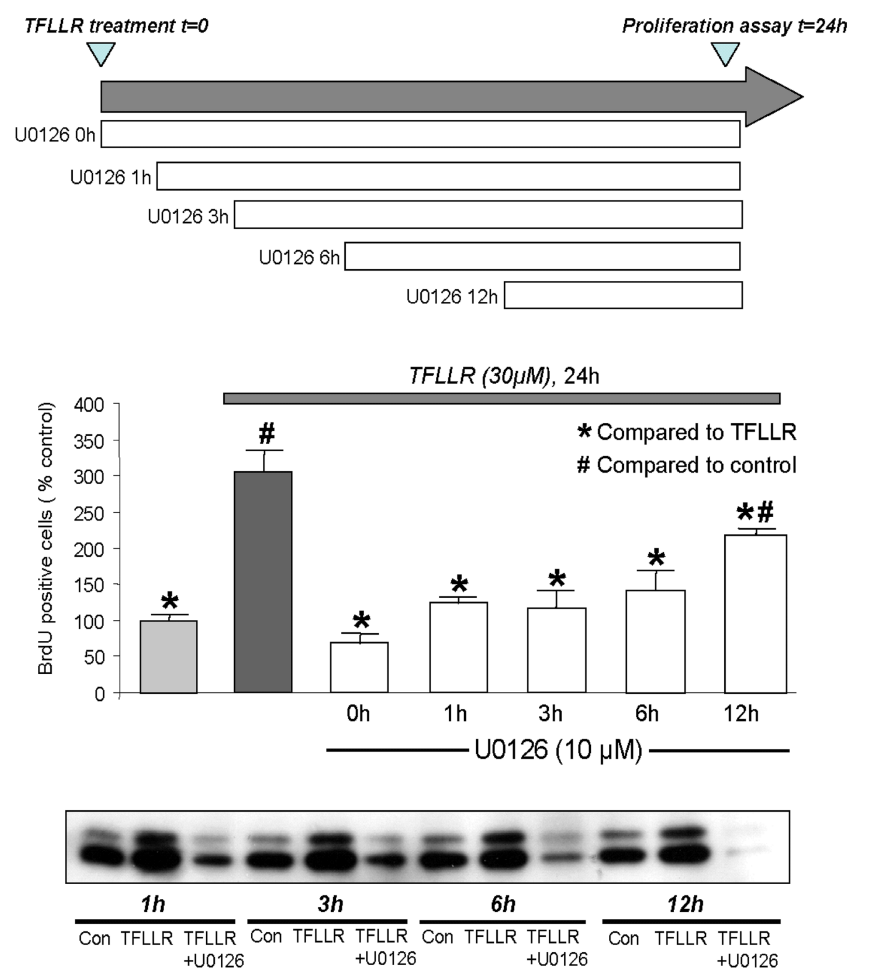

Figure 5. Block of ERK by delayed U0126 inhibits PAR-1-induced proliferation. Serumstarved murine primary cortical astrocytes were treated with TFLLR ( $30 \mu \mathrm{M})$ for $24 \mathrm{~h}$, and U0126 $(10 \mu \mathrm{M})$ was added at indicated times after TFLLR application (top). Delayed blockade of ERK activation with U0126 blocks TFLLR-induced proliferation, as measured with BrdU incorporation (middle; $n=8$; *,\# $p<0.001$; ANOVA). A representative immunoblot is shown below demonstrating the blockade of TFLLR-induced ERK phosphorylation by delayed U0126 treatment (bottom). Con, Control. Error bars represent SEM.

Because ERK is a key component for mitogenic signal transduction, we tested the effect of specific MAP kinase kinase (MEK) inhibitors [10 $\mu \mathrm{M}$ 1,4-diamino-2,3-dicyano-1,4-bis(o-aminophenylmercapto) butadiene (U0126) or $10 \mu \mathrm{M}$ 2-(2-amino-3methyoxyphenyl)-4H-1-benzopyran-4-one (PD98059)] on TFLLR-stimulated ERK phosphorylation in cultured astrocytes. As shown in Figure $4 B_{1}, 30 \mathrm{~min}$ of preincubation with U0126 completely suppressed ERK activation induced by $30 \mu \mathrm{M}$ TFLLR for up to $1 \mathrm{~h}(n=3)$ and totally blocked the TFLLR-induced proliferation in astrocytes $(n=6 ; p<0.001$; unpaired $t$ test) (Fig. $\left.4 B_{2}\right)$. Similar data were obtained with the MEK1 inhibitor PD98059 (10 $\mu \mathrm{M} ; n=6$; $p<0.001$ ), which decreased TFLLRinduced astrocyte proliferation from $246 \pm 3.4 \%$ above baseline to control levels $(89.9 \pm 2.1 \%)$. In contrast, an inhibitor of the p38 pathway, 4-(4-fluorophenyl)-2-(4-methylsulfonylphenyl)5-(4-pyridyl)-1H-imidazole (SB203580) (25 $\mu \mathrm{M} ; n=6$ ), was without effect on TFLLR-induced proliferation (TFLLR alone, $215.5 \pm 21.2 \%$; TFLLR with SB203580, $244.5 \pm 6.5 \%$ ), as expected given the lack of $\mathrm{p} 38$ stimulation by PAR-1 activation (Sorensen et al., 2003). Each inhibitor alone had little effect on baseline astrocyte proliferation (PD98059, $79.7 \pm 1.1 \%$; SB203580, $108.2 \pm 2.0 \%$ )

To evaluate whether the sustained ERK phosphorylation involved stabilization of phosphorylated ERK, we tested the effects of the MEK inhibitor U0126 applied after initial PAR-1 activation. Figure 5 summarizes the results of this experiment, which further confirm the ability of U0126 to reduce ERK activation. Delayed treatment of astrocytes with U0126 at 1,3, and $6 \mathrm{~h}$ after
TFLLR was added reduced ERK activation and proliferation to control levels ( $n=8$ per condition; $p<0.001$ ). At 12 h, U0126 significantly reduced proliferation and ERK activation, but the levels of proliferation were still significantly higher than control. These data suggest that continued MEK activity is required to fully stimulate proliferation. Because U0126 modestly decreased proliferation at $12 \mathrm{~h}$, stabilization of ERK activity may also contribute to the mitogenic response of astrocytes to PAR-1 activation. However, ERK activation was mostly suppressed by U0126 at $12 \mathrm{~h}$, suggesting that other signaling mediators may also be involved in PAR-1-induced astrocyte proliferation. Neither TFLLR (Fig. $4 A_{2}$ ) nor U0126 (data not shown) altered PAR-1 expression, as determined by reverse transcription (RT)-PCR analysis of astrocytes.

Cellular actions induced by PAR-1 activation typically involve one or several heterotrimeric G-protein subunits, such as $\mathrm{G}_{\beta} \gamma$, $\mathrm{G} \alpha_{\mathrm{q}} / \mathrm{G} \alpha_{11}, \mathrm{G} \alpha_{\mathrm{i}} / \mathrm{G}_{\mathrm{o}}$, and $\mathrm{G} \alpha_{12} / \mathrm{G} \alpha_{13}$ (Grand et al., 1996). To dissect the pathway(s) responsible for the coupling of TFLLR activation of PAR-1 to astrocyte proliferation, cultured astrocytes were treated with the $\mathrm{G} \alpha_{\mathrm{i} / \mathrm{o}}$ inhibitor pertussis toxin (PTX) (1 $\mu \mathrm{g} / \mathrm{ml}$ ) for $12 \mathrm{~h}$ before challenge with the agonist TFLLR. This treatment induced a partial reduction of ERK activation (Fig. $\left.4 C_{1}\right)(n=3)$ and a partial reduction of the proliferative effect of PAR-1 activation (Fig. $\left.4 C_{2}\right)(n=10 ; p<0.05$; unpaired $t$ test).

Similar experiments using the Rho kinase inhibitor $(R)-(+)-$ trans-N-(4-pyridyl)-4-(1-aminoethyl)-cyclohexanecarboxamide (Y27632) $(10 \mu \mathrm{M})$ (Welsh et al., 2001) suggest that activation of the $\mathrm{G} \alpha_{12} /$ Rho effector is not required for the coupling of TFLLR activation of PAR-1 to the phosphorylation of ERK in cultured astrocytes within the first hour (Fig. $4 D_{1}$ ). However, the $\mathrm{G} \alpha_{12} /$ Rho effector, Rho kinase, appears necessary to sustain activation of ERK beyond $1 \mathrm{~h}\left(\right.$ Fig. $\left.4 D_{1}\right)$, because Y27632 pretreatment blocks ERK activation at $12 \mathrm{~h}$ after TFLLR treatment. Y27632 also reduces astrocyte proliferation (Fig. $4 D_{2}$ ).

In most cell types, including glia, proliferation is controlled by the sequential expression of cyclins and activation of cyclindependent kinases (Durand et al., 1997; Roberts, 1999). Among $\mathrm{G}_{1}$-phase cyclins, the $\mathrm{D}$ types (including D1, D2, and D3) are growth factor responsive. Cyclins D1 and D3 are expressed in a large number of tissues, including the brain, whereas cyclin D2 seems to have more restricted patterns of expression (Bartkova et al., 1998). To further understand the molecular basis of the proliferative response of astrocytes to selective PAR-1 activation, we determined the kinetics of $\mathrm{G}_{1}$-phase cyclin expression in response to the PAR-1-activating peptide TFLLR. We evaluated the levels of expression of cyclin D1 and p2 ${ }^{\text {kip } 1}$, which also controls the cell cycle by counteracting cyclin D1 (Durand et al., 1997; Roberts, 1999). Preconfluent primary astrocytes were treated with $30 \mu \mathrm{M}$ TFLLR, and total cell lysates were prepared. RT-PCR analysis showed that the expression level of cyclin D1 mRNA was clearly increased after PAR-1 activation, with the maximum expression after $12-24 \mathrm{~h}$ (Fig. $6 A, E)(n=3)$. In contrast, the level of p $27^{\text {kip } 1}$ was not modified by TFLLR treatment (Fig. $6 B)(n=3)$. As summarized in Figure $6 E$, we observed a clear temporal correlation between TFLLR-stimulated cyclin D1 mRNA expression and increasing BrdU incorporation into proliferating astrocytes. To determine whether the increase in cyclin D1 mRNA is followed by an increase in protein synthesis, we performed an immunoblot experiment with a cyclin D1 antibody. As observed for the mRNA expression, treatment of astrocytes with TFLLR increased cyclin D1 protein expression at 3, 6, and $12 \mathrm{~h}$ (Fig. 6C) $(n=2)$. To determine whether ERK activation and Rho kinase activation control cyclin D1 protein expression in astrocytes, we tested by 
A

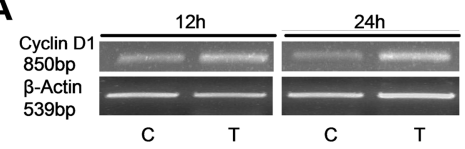

C

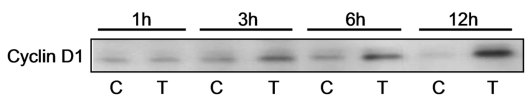

$\mathbf{E}$

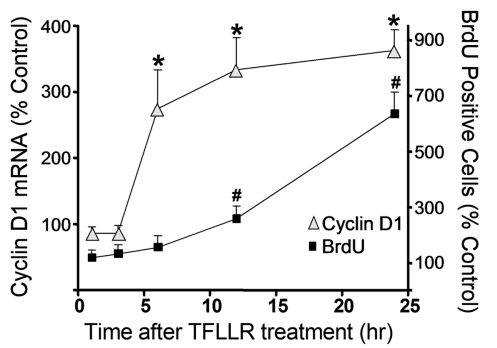

B
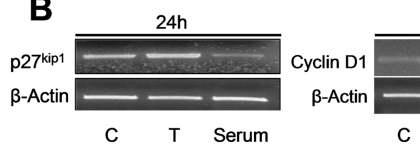

D
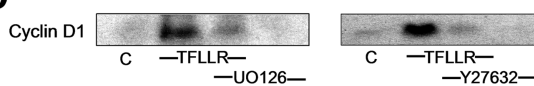

$\mathbf{F}$

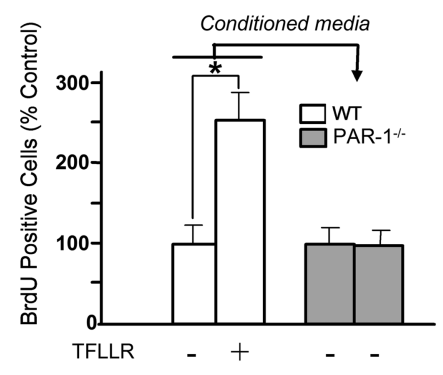

Figure 6. PAR-1 activation increases cyclin D1 expression. $A, B, \mathrm{RT}-\mathrm{PCR}$ is shown for cyclin D1, $\mathrm{p2} 7^{\mathrm{kip} 1}$, and $\beta$-actin transcripts. Total mRNA from control (C) or TFLLR (T;30 $\mu \mathrm{m}$ )-treated astrocyte cultures in serum-free medium was harvested 1,3,6, 12, and $24 \mathrm{~h}$ after treatment and subjected to RT-PCR (see Materials and Methods). PAGE for one of three independent experiments shows cyclin D1 upregulation at 12 and $24 \mathrm{~h}$, with no change in p $27^{\text {kip } 1}$ mRNA levels. $B$, Left, Total p $27^{\text {kip } 1}$ mRNA levels were not altered by TFLLR treatment. Right, Total mRNA obtained from TFLLR-treated astrocyte cultures with or without U0126 (30 min before and during TFLLR treatment). TFLLR-induced cyclin D1 expression is blocked by treatment with U0126 (top). The results of densitometry analysis of cyclin D1 mRNA expression $(\triangle)$ are summarized below $(\boldsymbol{E}) . \boldsymbol{C}, \boldsymbol{D}$, Representative immunoblots of cyclin D1 protein expression from three independent experiments. An immunoblot of cortical astrocytes at $1,3,6$, or $12 \mathrm{~h}$ after control or TFLLR treatment shows cyclin D1 protein upregulation from 3 to $12 \mathrm{~h}(C ; n=2)$. An immunoblot of cortical astrocytes pretreated with U0126 or Y27632 and treated with TFLLR for $24 \mathrm{~h}$ shows blockade of cyclin D1 protein upregulation (D). E, The results of densitometry analysis of cyclin D1 mRNA expression $(\triangle)$ show a correlation to the time course of astrocytic proliferation $(\square)(n=$ 8) after TFLLR treatment, as measured by cell counting of BrdU-positive cells. The asterisks indicate a significant difference from control in the same time for cyclin D1 expression; the number sign indicates a significant difference from control in the same time for BrdU incorporation. $\boldsymbol{F}$, Cortical astrocytes from wild-type mice were cultured for $12 \mathrm{~h}$ in the presence of TFLLR ( $30 \mu \mathrm{M})$, and conditioned media were collected and replaced by fresh medium. The asterisk indicates a significant difference from control condition (without TFLLR). Proliferation assays were performed $12 \mathrm{~h}$ later by evaluating BrdU incorporation. Cortical astrocytes from PAR1 ${ }^{-/}$- mice were subsequently incubated with conditioned media from wild-type (WT) astrocytes treated with TFLLRfor $24 \mathrm{~h}$, and a proliferation assay by BrdU incorporation was performed $(n=8)$. Error bars represent SEM.

Western blotting the effect of U0126 and Y27632 on the TFLLRinduced expression of cyclin D1 (Fig. 6D). As observed for the proliferation assay, the treatment of astrocytes with the ERK inhibitor U0126 $(n=3)$ or the Rho kinase inhibitor Y27632 $(n=3)$ blocked the protein expression of cyclin D1. Together, these results suggest that PAR-1 agonist-induced cyclin D1 expression and proliferation requires ERK and Rho kinase activation.

\section{PAR-1 activation does not reflect release of mitogens}

One alternative hypothesis to our conclusion that PAR-1initiated Rho-ERK signaling elevates cyclin D1 to control astrocyte proliferation is the possibility that the proliferation observed reflects PAR-1-stimulated release of a growth factor(s) from astrocytes (Meli et al., 2001). A related alternative hypothesis is that contaminating microglia in our culture respond to PAR-1 activation with release of a mitogenic agent that stimulates astrocyte proliferation. We tested the first possibility by adding conditioned media from wild-type astrocytes treated with TFLLR (12 h) onto astrocytes cultured from $P A R 1^{-/-}$mice, which should respond to other growth factors but will not respond to residual TFLLR in the conditioned media. As shown in Figure $6 F$, the conditioned media from wild-type astrocytes treated with TFLLR did not induce proliferation of PAR $1^{-1-}$ astrocytes $(n=8)$. As a positive control, we verified that $P A R 1^{-1-}$ astrocytes responded to known mitogens with increased cell division. Application of 30 $\mu \mathrm{M}$ lysophosphatidic acid stimulated proliferation, as measured by incorporation of $\left[{ }^{3} \mathrm{H}\right]$ thymidine, by $5.16 \pm 0.8$-fold. These data suggest that astrocytes do not release a stable mitogenic agent after TFLLR treatment and thus further support our working hypothesis.

Microglia, similarly to astrocytes, show ERK phosphorylation in response to PAR- 1 activation and are known to release cytokines and growth factors when activated (Suo et al., 2003). We therefore tested the potential cross talk between microglia and astrocytes in response to PAR-1 activation by coculturing purified $P A R 1^{-1-}$ or littermate wild-type astrocytes with microglia from either $P A R 1^{-1-}$ or littermate wild-type animals. Figure 7 summarizes the proliferative response of astrocytes to $10 \mathrm{~nm}$ thrombin when cultured alone or with $P A R 1^{-/-}$or wild-type microglia. Thrombin significantly stimulated BrdU incorporation into GFAPpositive wild-type cells in all conditions, suggesting that activation of microglial PAR-1 is not necessary for astrocyte proliferation. Interestingly, there was a slight enhancement of the proliferative response to thrombin in the presence of $P A R 1^{-/-}$ microglia, suggesting that thrombin may act on wild-type microglia to slow astrocyte proliferation. However, activation of PAR-1 by the selective peptide activator TFLLR produced identical levels of astrocyte proliferation under the same conditions ( $n=3$; data not shown), suggesting that the enhanced effect seen with thrombin may reflect other substrates or PARs. As a complement to this experiment, $P A R 1^{-1-}$ astrocytes did not show enhanced proliferation in response to PAR-1 agonists when cocultured with wild-type microglia, whereas the wild-type microglia in these cocultures showed significant proliferation ( $165 \pm 14 \%$ of control; $p \leq 0.02 ; n=8)$. Together, these experiments demonstrate that activation of microglial PAR-1 is not required for astrocytic proliferation in response to PAR-1 agonists.

\section{Discussion}

The protective blood-brain barrier normally allows the diffusion of small molecules and transport of essential nutrients into brain parenchyma but excludes large proteins and other blood constituents from the interstitial space of the CNS. However, head trauma, stroke, status epilepticus, and other pathological conditions can all compromise the integrity of this barrier and allow blood proteins such as albumin to gain access to the extracellular spaces that surround neurons and glia. Given their possible entry into brain tissue during cerebrovascular insult, the effects of blood-derived proteases such as thrombin in the CNS have come under increasing scrutiny (Akiyama et al., 1992; Cunningham et al., 1993; Nishino et al., 1993; Lee et al., 1996; Gingrich and Traynelis, 2000). Preliminary data show that subdural hematoma can elevate thrombin levels 250 -fold in CSF from 100 pM to $25 \mathrm{nM}$ for a period of $>1$ week (Suzuki et al., 1992), suggesting that appreciable amounts of thrombin can be generated and persist at sites of cerebrovascular injury. When bleeding occurs directly 
$\mathbf{A}$
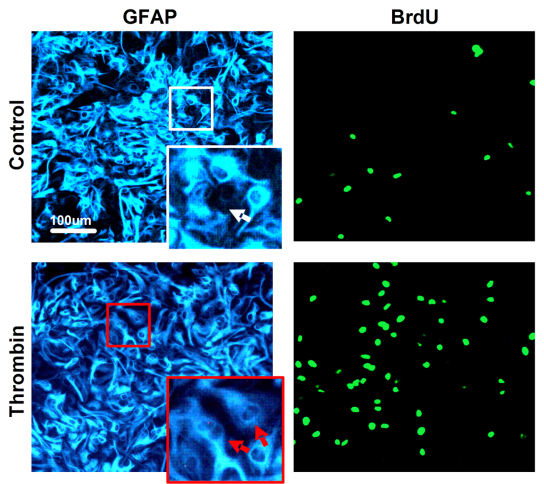

B

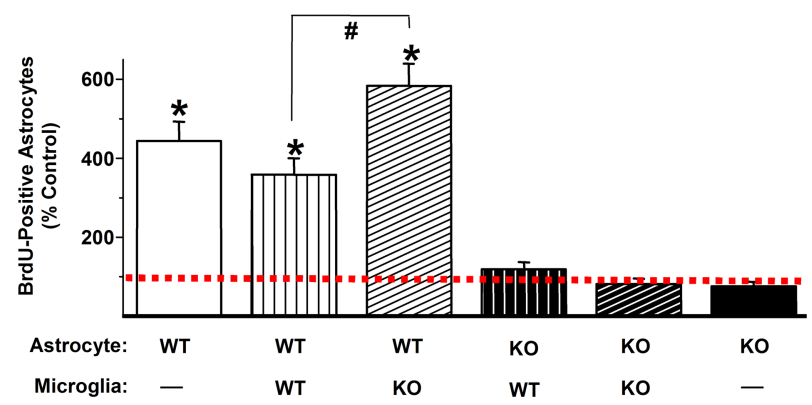

Figure 7. Effect of microglial cells on thrombin-induced astrocyte proliferation in vitro. $\boldsymbol{A}$, Immunostaining for GFAP (Marina Blue 460) and BrdU incorporation (Alexa Fluor 488) in control and $\alpha$-thrombin-treated cocultures of wild-type astrocytes and wild-type microglia illustrate increased BrdU-positive astrocytes in response to $\alpha$-thrombin $(1 \mathrm{U} / \mathrm{ml}$ ) (red arrows). Distinguishing GFAP-positive, BrdU-positive astrocytes (red arrows) from GFAP-negative, BrdUpositive cells (white arrows) allowed for identification and counting of proliferating astrocytes in cocultures. $\boldsymbol{B}$, Compared with untreated wild-type (WT) astrocytes (marked with a dotted line at $100 \%)$, all $\alpha$-thrombin $(1 \mathrm{U} / \mathrm{ml})$-treated wild-type astrocytes exhibited significantly increased BrdU incorporation, regardless of microglial cell absence or the presence of wild-type or $P A R 1^{-1-}$ [knock-out (KO)] microglial cells ( $n=6$; $^{*} p<0.0001$; unpaired $t$ test). In contrast, all $P A R 1^{-/-}$astrocyte cultures were similar to untreated wild-type astrocytes. Cocultures of wild-type astrocytes with $P A R 1^{-1-}$ microglia modestly increased BrdU-positive astrocytes compared with cocultures of wild-type astrocytes and wild-type microglia $\left(n=6{ }^{*} p<0.005\right.$; unpaired $t$ test). Error bars represent SEM.

within the brain tissue, active thrombin and other proteases will freely penetrate the interneuronal spaces by diffusion, until clotting closes the injured vessels and thrombin becomes depleted from the clots. Because prothrombin circulates in blood at high concentrations $(\sim 1 \mu \mathrm{M})$ (Lee et al., 1996), and because vascular injury triggers its rapid conversion to thrombin, direct entry of thrombin into interstitial space could result in the activation of neuronal and glial PAR-1, given that the thrombin $\mathrm{EC}_{50}$ for activation of PAR-1 is in the subnanomolar range (Vu et al., 1991). Thus, it is imperative to understand all actions of thrombin and PAR-1 on each component of the injury process.

Considerable evidence suggests that PAR-1 activation can influence neuronal survival. A number of studies exist showing both harmful as well as beneficial effects of PAR-1 activation (Akiyama et al., 1992; Festoff et al., 1992; Cunningham et al., 1993; Gingrich and Traynelis, 2000; Vivien and Buisson, 2000; Shibata et al., 2001; Cheng et al., 2003; Junge et al., 2003; Mosnier and Griffin, 2003; Ruf, 2003; Guo et al., 2004; Olson et al., 2004). Furthermore, thrombin seems to induce microglial activation by induction of DNA synthesis as well as production of nitric oxide and tumor necrosis factor- $\alpha$ (Ryu et al., 2000; Suo et al., 2002). Many groups have also demonstrated that PAR-1 activation stimulates astrocytes to transform from their normally stellate shape into a polygonal morphology (Beecher et al., 1994; Grab- ham and Cunningham, 1995; Suidan et al., 1997; Pindon et al., 1998). In addition, thrombin also induces endothelin-1 and nerve growth factor secretion from astrocytes (Ehrenreich et al., 1993; Neveu et al., 1993; Debeir et al., 1996). In this study, we turned our attention away from the question of how PAR-1 activation influences neuronal survival and instead focused on the role of PAR-1 activation in astrogliosis. Because proteolytic activators of PAR-1, including thrombin, plasmin, factor Xa, and activated protein $\mathrm{C}$, have a variety of effects beyond PAR-1 cleavage, we used the selective PAR-1 peptide agonist TFLLR (Hollenberg et al., 1997). This peptide has no catalytic activity and, unlike thrombin, does not bind to the hirudin-like domain of PAR-1.

Our most important finding is that PAR-1 activation in resting astrocytes plays a key role in the process of gliotic scar formation by stimulating astrocyte proliferation after brain injury. We also demonstrated that a PAR-1-selective agonist can induce short-term astrogliosis in vivo and that the recruitment of the MAPK pathway through $\mathrm{G} \alpha_{\mathrm{i} / \mathrm{o}}$ is essential for coupling this receptor to cyclin D1 expression and consequently astrocyte proliferation. In addition, our pharmacological data suggest that the activation of Rho kinase pathways also plays a key role in regulating the proliferative response through a stabilization of MAPK activation, which controls cyclin D1 expression. All of these conclusions are supported by multiple lines of experimentation in vivo and in vitro.

\section{PAR-1 activation in vivo}

Previous work has suggested that thrombin may play multiple roles in the glial response to injury. Indeed, infusion of exogenous thrombin into the rat caudate nucleus causes reactive gliosis and scar formation, infiltration of inflammatory cells, proliferation of mesenchymal cells, induction of angiogenesis, and other effects that resemble inflammation (Nishino et al., 1993). Although these intriguing data suggest that thrombin may be a candidate trigger or regulator of the processes of gliosis in vivo, Wang et al. (2002b) showed that thrombin can use PAR-1, PAR-3, and PAR-4 for the signal transduction in astrocytes, making it difficult to fully interpret the results from Nishino et al. (1993). Our data demonstrate that PAR-1 activation plays a key role in the initial phases of the astrocytic response to injury in vivo. Moreover, a sustained activation of the ERK/MAPK signaling pathway has been shown in perilesional reactive glia after a forebrain stab lesion and suggests a critical role for this cascade in astrogliosis (Carbonell and Mandell, 2003). This sustained activation of ERK is consistent with the effects of PAR-1 activation described here.

Interestingly, PAR-1 involvement in glial scar formation has been suggested previously in the wobbler (wr) mutation model, which shows muscular atrophy associated with developmental motoneuron degeneration. Wobbler is detectable in the third week of life, when homozygotes (wr/wr) exhibit prominent gliosis and significant motoneuron loss (Laage et al., 1988). In wr/wr mice, reactive astrogliosis was correlated with increased PAR-1 protein expression (Festoff et al., 2000). Our data suggest that the increased PAR-1 expression in the wr/wr mice might explain, in part, the prominent astrogliosis observed in these animals. Moreover, a developmental distribution of GFAP-positive astrocytes in the spinal cord of wobbler mice during the course of the disease has shown that astrocyte overgrowth may be a fundamental feature of the wobbler disease, and is consistent with the function of PAR-1 in astrocytic proliferation (Hantaz-Ambroise et al., 1994). 


\section{Cellular mechanism underlying PAR-1-triggered gliosis}

The mechanisms by which PAR-1 stimulates astrocyte proliferation appear related to the ability of PAR-1 to control ERK activation. These results are in line with previous reports that thrombin acts as a mitogen for astrocytes through PAR-1 activation (Grabham and Cunningham, 1995). This and other studies (Wang et al., 2002b; Sorensen et al., 2003) have demonstrated that stimulation of PAR-1 rapidly activates ERK1/ERK2 and that inhibition of these pathways with the MEK inhibitor U0126 completely inhibits the proliferative response to the PAR-1 agonist. Although several studies (Teixeira et al., 2000; Wang et al., 2002b; Carbonell and Mandell, 2003) have examined the effect of ERK signaling in astrocyte proliferation and the relationships between astrocyte proliferation and cell-cycle proteins, our data are the first to suggest a link between these two processes. To establish this link, the coupling of PAR-1 activation and proliferation was pharmacologically dissected using inhibitors of PAR-1 signaling pathways. PTX and Y27632 were used to define the role for $\mathrm{G} \alpha_{\mathrm{i} / \mathrm{o}}$ and Rho kinase pathways in these processes, respectively. Both PTX and Y27632 disrupted astrocyte proliferation but displayed differential effects on MAPK activation. Our data show that $\mathrm{G} \alpha_{\mathrm{i} / \mathrm{o}}$ activation is necessary to initiate the MAPK cascade and that Rho activation appears to stabilize ERK activation, because the Rho kinase inhibitor Y27632 is without effect on ERK activation in the early phase, but blocks sustained ERK activation.

We propose that extravasation of blood-derived PAR-1 activators during blood-brain barrier breakdown or intracerebral hemorrhage leads to activation of PAR-1-linked $\mathrm{G} \alpha_{\mathrm{i} / \mathrm{o}}$ (Fig. $4 C_{1}$, $C_{2}$ ) (Wang et al., 2002b) and $\mathrm{G} \alpha_{\mathrm{q} / 11}$ (Wang et al., 2002b), which induce the rapid activation of ERK MAP kinases in part by $\beta \gamma$ signaling. PAR-1-linked activation of $\mathrm{G} \alpha_{12} / \mathrm{G} \alpha_{13}$ signaling subsequently stabilizes ERK activation through Rho kinase. Activation of the MEK/ERK pathway has been linked to the induction of cyclin D1 mRNA in many cell lines (Lavoie et al., 1996; Cheng et al., 1998), and our data show that PAR-1 activation induces an increase in cyclin D1 expression. This is correlated with an increase in astrocyte proliferation independent of the cell-cycle inhibitor $\mathrm{p} 27^{\mathrm{kip} 1}$. Thus, our data support a multistep pathway linking extravasation of PAR-1 activators to control of biochemical checkpoints in the cell cycle [see the supplemental figure, which assembles these data into a working hypothesis (available at www. jneurosci.org as supplemental material)].

Interestingly, Rho signaling has been shown recently to maintain ERK activation in a fibroblast cell line (Welsh et al., 2001). Moreover, the cooperative effects we see for PAR-1 signaling pathways in the regulation of sustained ERK activity have also been observed between activated receptor tyrosine kinases (RTKs) and integrin in cultured fibroblasts and in chick chorioallantoic membranes (Eliceiri et al., 1998; Roovers et al., 1999). Precedent exists for cooperation between RTKs and integrins to regulate the cell-cycle progression through the $G_{1}$ phase, and this cooperation is reflected in the regulation of both cyclin D1 and the cyclin-dependent kinase-inhibitory protein p27 $7^{\text {kip } 1}$ (Welsh et al., 2001). Thus, the effects of PAR-1 on astrocyte proliferation share a subset of mechanistic features of proliferation in other tissues.

\section{References}

Akiyama H, Ikeda K, Kondo H, McGeer PL (1992) Thrombin accumulation in brains of patients with Alzheimer's disease. Neurosci Lett 146:152-154.

Ali C, Nicole O, Docagne F, Lesne S, MacKenzie ET, Nouvelot A, Buisson A, Vivien D (2000) Ischemia-induced interleukin-6 as a potential endogenous neuroprotective cytokine against NMDA receptor-mediated excitotoxicity in the brain. J Cereb Blood Flow Metab 20:956-966.
Ayata C, Ayata G, Hara H, Matthews RT, Beal MF, Ferrante RJ, Endres M, Kim A, Christie RH, Waeber C, Huang PL, Hyman BT, Moskowitz MA (1997) Mechanisms of reduced striatal NMDA excitotoxicity in type I nitric oxide synthase knock-out mice. J Neurosci 17:6908-6917.

Bartkova J, Lukas J, Strauss M, Bartek J (1998) Cyclin D3: requirement for G1/S transition and high abundance in quiescent tissues suggest a dual role in proliferation and differentiation. Oncogene 17:1027-1037.

Beecher KL, Andersen TT, Fenton II JW, Festoff BW (1994) Thrombin receptor peptides induce shape change in neonatal murine astrocytes in culture. J Neurosci Res 37:108-115.

Bottazzi ME, Zhu X, Bohmer RM, Assoian RK (1999) Regulation of p21(cip1) expression by growth factors and the extracellular matrix reveals a role for transient ERK activity in G1 phase. J Cell Biol 146:1255-1264.

Carbonell WS, Mandell JW (2003) Transient neuronal but persistent astroglial activation of ERK/MAP kinase after focal brain injury in mice. J Neurotrauma 20:327-336.

Cheng M, Sexl V, Sherr CJ, Roussel MF (1998) Assembly of cyclin D-dependent kinase and titration of p27Kip1 regulated by mitogenactivated protein kinase kinase (MEK1). Proc Natl Acad Sci USA 95:1091-1096.

Cheng T, Liu D, Griffin JH, Fernandez JA, Castellino F, Rosen ED, Fukudome K, Zlokovic BV (2003) Activated protein C blocks p53-mediated apoptosis in ischemic brain endothelium and is neuroprotective. Nat Med 9:338-342.

Connolly AJ, Ishihara H, Kahn ML, Farese Jr RV, Coughlin SR (1996) Role of the thrombin receptor in development and evidence for a second receptor. Nature 381:516-519.

Cunningham DD, Pulliam L, Vaughan PJ (1993) Protease nexin-1 and thrombin: injury-related processes in the brain. Thromb Haemost 70:168-171.

Debeir T, Gueugnon J, Vige X, Benavides J (1996) Transduction mechanisms involved in thrombin receptor-induced nerve growth factor secretion and cell division in primary cultures of astrocytes. J Neurochem 66:2320-2328.

Dihanich M, Kaser M, Reinhard E, Cunningham D, Monard D (1991) Prothrombin mRNA is expressed by cells of the nervous system. Neuron 6:575-581.

Donovan FM, Cunningham DD (1998) Signaling pathways involved in thrombin-induced cell protection. J Biol Chem 273:12746-12752.

Durand B, Gao FB, Raff M (1997) Accumulation of the cyclin-dependent kinase inhibitor $\mathrm{p} 27 / \mathrm{Kip} 1$ and the timing of oligodendrocyte differentiation. ЕMBO J 16:306-317.

Dyer MA, Cepko CL (2001) p27Kip1 and p57Kip2 regulate proliferation in distinct retinal progenitor cell populations. J Neurosci 21:4259-4271.

Ehrenreich H, Costa T, Clouse KA, Pluta RM, Ogino Y, Coligan JE, Burd PR (1993) Thrombin is a regulator of astrocytic endothelin-1. Brain Res 600:201-207.

Eliceiri BP, Klemke R, Stromblad S, Cheresh DA (1998) Integrin alphavbeta3 requirement for sustained mitogen-activated protein kinase activity during angiogenesis. J Cell Biol 140:1255-1263.

Fawcett JW, Asher RA (1999) The glial scar and central nervous system repair. Brain Res Bull 49:377-391.

Fenton II JW, Bing DH (1986) Thrombin active-site regions. Semin Thromb Hemost 12:200-208.

Festoff BW, Rao JS, Chen M (1992) Protease nexin I, thrombin- and urokinase-inhibiting serpin, concentrated in normal human cerebrospinal fluid. Neurology 42:1361-1366.

Festoff BW, D'Andrea MR, Citron BA, Salcedo RM, Smirnova IV, AndradeGordon P (2000) Motor neuron cell death in wobbler mutant mice follows overexpression of the G-protein-coupled, protease-activated receptor for thrombin. Mol Med 6:410-429.

Gingrich MB, Traynelis SF (2000) Serine proteases and brain damage-is there a link? Trends Neurosci 23:399-407.

Gingrich MB, Junge CE, Lyuboslavsky P, Traynelis SF (2000) Potentiation of NMDA receptor function by the serine protease thrombin. J Neurosci 20:4582-4595.

Grabham P, Cunningham DD (1995) Thrombin receptor activation stimulates astrocyte proliferation and reversal of stellation by distinct pathways: involvement of tyrosine phosphorylation. J Neurochem 64:583-591. 
Grand RJ, Turnell AS, Grabham PW (1996) Cellular consequences of thrombin-receptor activation. Biochem J 313:353-368.

Guo H, Liu D, Gelbard H, Cheng T, Insalaco R, Fernandez JA, Griffin JH, Zlokovic BV (2004) Activated protein C prevents neuronal apoptosis via protease activated receptors 1 and 3. Neuron 41:563-572.

Hamill CE, Goldshmidt A, Nicole O, McKeon RJ, Brat DJ, Traynelis SF (2005) Glial reactivity following damage: implications for scar formation and neuronal recovery. Clin Neurosurg, in press.

Hantaz-Ambroise D, Blondet B, Murawsky M, Rieger F (1994) Abnormal astrocyte differentiation and defective cellular interactions in wobbler mouse spinal cord. J Neurocytol 23:179-192.

Hatten ME, Liem RK, Shelanski ML, Mason CA (1991) Astroglia in CNS injury. Glia 4:233-243.

Hollenberg MD, Saifeddine M, al-Ani B, Kawabata A (1997) Proteinaseactivated receptors: structural requirements for activity, receptor crossreactivity, and receptor selectivity of receptor-activating peptides. Can J Physiol Pharmacol 75:832-841.

Hou YJ, Yu AC, Garcia JM, Aotaki-Keen A, Lee YL, Eng LF, Hjelmeland LJ, Menon VK (1995) Astrogliosis in culture. IV. Effects of basic fibroblast growth factor. Neurosci Res 40:359-370.

Junge CE, Sugawara T, Mannaioni G, Alagarsamy S, Conn PJ, Brat DJ, Chan PH, Traynelis, SF (2003) The contribution of protease-activated receptor 1 to neuronal damage caused by transient focal cerebral ischemia. Proc Natl Acad Sci USA 100:13019-13024.

Junge CE, Lee CJ, Hubbard KB, Zhang Z, Olson JJ, Hepler JR, Brat DJ, Traynelis SF (2004) Protease-activated receptor-1 in human brain: localization and functional expression in astrocytes. Exp Neurol 188:94-103.

Kaneko R, Hagiwara N, Leader K, Sueoka N (1994) Glial-specific cAMP response of the glial fibrillary acidic protein gene cell lines. Proc Natl Acad Sci USA 91:4529-4533.

Laage S, Zobel G, Jockusch H (1988) Astrocyte overgrowth in the brain stem and spinal cord of mice affected by spinal atrophy, wobbler. Dev Neurosci 10:190-198.

Lavoie JN, L'Allemain G, Brunet A, Muller R, Pouyssegur J (1996) Cyclin D1 expression is regulated positively by the $\mathrm{p} 42 / \mathrm{p} 44 \mathrm{MAPK}$ and negatively by the p38/HOGMAPK pathway. J Biol Chem 271:20608-20616.

Lee KR, Colon GP, Betz AL, Keep RF, Kim S, Hoff JT (1996) Edema from intracerebral hemorrhage: the role of thrombin. J Neurosurg 84:91-96.

Liberto CM, Albrecht PJ, Herx LM, Yong VW, Levison SW (2004) Proregenerative properties of cytokine-activated astrocytes. J Neurochem 89:1092-1100.

Liu L, Rudin M, Kozlova EN (2000) Glial cell proliferation in the spinal cord after dorsal rhizotomy or sciatic nerve transection in the adult rat. Exp Brain Res 131:64-73.

Macfarlane SR, Seatter MJ, Kanke T, Hunter GD, Plevin R (2001) Proteinase-activated receptors. Pharmacol Rev 53:245-282.

Mackie EJ, Pagel CN, Smith R, de Niese MR, Song SJ, Pike RN (2002) Protease-activated receptors: a means of converting extracellular proteolysis into intracellular signals. IUBMB Life 53:277-281.

Matyash M, Matyash V, Nolte C, Sorrentino V, Kettenmann H (2002) Requirement of functional ryanodine receptor type 3 for astrocyte migration. FASEB J 16:84-86.

Meli R, Raso GM, Cicala C, Esposito E, Fiorino F, Cirino G (2001) Thrombin and PAR-1 activating peptide increase iNOS expression in cytokinestimulated C6 glioma cells. J Neurochem 79:556-563.

Menet V, Prieto M, Privat A, Gimenez y Ribotta M (2003) Axonal plasticity and functional recovery after spinal cord injury in mice deficient in both glial fibrillary acidic protein and vimentin genes. Proc Natl Acad Sci USA 100:8999-9004.

Mosnier LO, Griffin JH (2003) Inhibition of staurosporine-induced apoptosis of endothelial cells by activated protein $\mathrm{C}$ requires proteaseactivated receptor- 1 and endothelial cell protein $\mathrm{C}$ receptor. Biochem J 373:65-70.

Neveu I, Jehan F, Jandrot-Perrus M, Wion D, Brachet P (1993) Enhancement of the synthesis and secretion of nerve growth factor in primary cultures of glial cells by proteases: a possible involvement of thrombin. J Neurochem 60:858-867

Nishino A, Suzuki M, Ohtani H, Motohashi O, Umezawa K, Nagura H, Yoshimoto T (1993) Thrombin may contribute to the pathophysiology of central nervous system injury. J Neurotrauma 10:167-179.

Olson EE, Lyuboslavsky P, Traynelis SF, McKeon RJ (2004) PAR-1 deficiency protects against neuronal damage and neurologic deficits after unilateral cerebral hypoxia/ischemia. J Cereb Blood Flow Metab 24:964-971.

Pindon A, Festoff BW, Hantai D (1998) Thrombin-induced reversal of astrocyte stellation is mediated by activation of protein kinase $\mathrm{C}$ beta-1. Eur J Biochem 255:766-774.

Rasmussen UB, Vouret-Craviari V, Jallat S, Schlesinger Y, Pages G, Pavirani A, Lecocq JP, Pouyssegur J, Van Obberghen-Schilling E (1991) cDNA cloning and expression of a hamster alpha-thrombin receptor coupled to $\mathrm{Ca}^{2+}$ mobilization. FEBS Lett 288:123-128.

Ridet JL, Malhotra SK, Privat A, Gage FH (1997) Reactive astrocytes: cellular and molecular cues to biological function. Trends Neurosci 20:570-577.

Roberts JM (1999) Evolving ideas about cyclins. Cell 98:129-132.

Rogove AD, Siao C, Keyt B, Strickland S, Tsirka SE (1999) Activation of microglia reveals a non-proteolytic cytokine function for tissue plasminogen activator in the central nervous system. J Cell Sci 112:4007-4016.

Roovers K, Assoian RK (2000) Integrating the MAP kinase signal into the G1 phase cell cycle machinery. BioEssays 22:818-826.

Roovers K, Davey G, Zhu X, Bottazzi ME, Assoian RK (1999) Alpha5betal integrin controls cyclin D1 expression by sustaining mitogen-activated protein kinase activity in growth factor-treated cells. Mol Biol Cell 10:3197-3204.

Rose K, Goldberg MP, Choi DW (1993) In vitro biological methods (Tyson CA, Frazier JM, eds), pp 46-60. San Diego: Academic.

Rudge JS, Smith GM, Silver J (1989) An in vitro model of wound healing in the CNS: analysis of cell reaction and interaction at different ages. Exp Neurol 103:1-16.

Ruf W (2003) PAR-1 signaling: more good than harm? Nat Med 9:258-260.

Ryu J, Pyo H, Jou I, Joe E (2000) Thrombin induces NO release from cultured rat microglia via protein kinase $\mathrm{C}$, mitogen-activated protein kinase, and NF-kappa B. J Biol Chem 275:29955-29959.

Shibata M, Kumar SR, Amar A, Fernandez JA, Hofman F, Griffin JH, Zlokovic BV (2001) Anti-inflammatory, antithrombotic, and neuroprotective effects of activated protein $\mathrm{C}$ in a murine model of focal ischemic stroke. Circulation 103:1799-1805.

Silver J, Miller JH (2004) Regeneration beyond the glial scar. Nat Rev Neurosci 5:146-156.

Soifer SJ, Peters KG, O'Keefe J, Coughlin SR (1994) Disparate temporal expression of the prothrombin and thrombin receptor genes during mouse development. Am J Pathol 144:60-69.

Sorensen SD, Nicole O, Peavy RD, Montoya LM, Lee CJ, Murphy TJ, Traynelis SF, Hepler JR (2003) Common signaling pathways link activation of murine PAR-1, LPA, and S1P receptors to proliferation of astrocytes. Mol Pharmacol 64:1199-1209.

Striggow F, Riek M, Breder J, Henrich-Noack P, Reymann KG, Reiser G (2000) The protease thrombin is an endogenous mediator of hippocampal neuroprotection against ischemia at low concentrations but causes degeneration at high concentrations. Proc Natl Acad Sci USA 97:2264-2269.

Suidan HS, Nobes CD, Hall A, Monard D (1997) Astrocyte spreading in response to thrombin and lysophosphatidic acid is dependent on the Rho GTPase. Glia 21:244-252.

Suo Z, Wu M, Ameenuddin S, Anderson HE, Zoloty JE, Citron BA, AndradeGordon P, Festoff BW (2002) Participation of protease-activated receptor-1 in thrombin-induced microglial activation. J Neurochem 80:655-666.

Suo Z, Wu M, Citron BA, Gao C, Festoff BW (2003) Persistent proteaseactivated receptor 4 signaling mediates thrombin-induced microglial activation. J Biol Chem 278:31177-31183.

Suzuki M, Ogawa A, Sakurai Y, Nishino A, Venohara K, Mizoi K, Yoshimoto T (1992) Thrombin activity in cerebrospinal fluid after subarachnoid hemorrhage. Stroke 23:1181-1182.

Teixeira A, Chaverot N, Strosberg AD, Cazaubon S (2000) Differential regulation of cyclin D1 and D3 expression in the control of astrocyte proliferation induced by endothelin-1. J Neurochem 74:1034-1040.

Vivien D, Buisson A (2000) Serine protease inhibitors: novel therapeutic targets for stroke? J Cereb Blood Flow Metab 20:755-764.

Vu TK, Hung DT, Wheaton VI, Coughlin SR (1991) Molecular cloning of a functional thrombin receptor reveals a novel proteolytic mechanism of receptor activation. Cell 64:1057-1068. 
Wang H, Ubl JJ, Reiser G (2002a) Four subtypes of protease-activated receptors, co-expressed in rat astrocytes, evoke different physiological signaling. Glia 37:53-63.

Wang H, Ubl JJ, Stricker R, Reiser G (2002b) Thrombin (PAR-1)-induced proliferation in astrocytes via MAPK involves multiple signaling pathways. Am J Physiol Cell Physiol 283:C1351-C1364.

Weber JD, Hu W, Jefcoat Jr SC, Raben DM, Baldassare JJ (1997) Ras-stimulated extracellular signal-related kinase 1 and RhoA activities coordinate plateletderived growth factor-induced G1 progression through the independent regulation of cyclin D1 and p27. J Biol Chem 272:32966-32971.

Weinstein JR, Gold SJ, Cunningham DD, Gall CM (1995) Cellular localization of thrombin receptor mRNA in rat brain: expression by mesence- phalic dopaminergic neurons and codistribution with prothrombin mRNA. J Neurosci 15:2906-2919.

Welsh CF, Roovers K, Villanueva J, Liu Y, Schwartz MA, Assoian RK (2001) Timing of cyclin D1 expression within G1 phase is controlled by Rho. Nat Cell Biol 3:950-957.

Wu QY, Sheehan JP, Tsiang M, Lentz SR, Birktoft JJ, Sadler JE (1991) Single aminoacid substitutionsdissociatefibrinogen-clottingand thrombomodulinbinding activities of human thrombin. Proc Natl Acad Sci USA 88:6775-6779.

XiG, Wu J, Jiang Y, Hua Y, Keep RF, HoffJT (2003) Thrombin preconditioning upregulates transferrin and transferrin receptor and reduces brain edema induced by lysed red blood cells. Acta Neurochir Suppl 86:449-452. 